\title{
Facial Dog Bites: 10 Case Report
}

\author{
Zine el Abidine $\mathrm{H}^{* 1}$, Moustaader $\mathrm{H}^{2}$, Bajja $\mathrm{MY}^{1}$, Rouadi $\mathrm{S}^{1}$, Abada $\mathrm{R}^{1}$, Roubal $\mathrm{M}^{1}$ and Mahtar $\mathrm{M}^{1}$ \\ ${ }^{1}$ Department of ENT and Neck Surgery, "20 August” Hospital, Ibn Rochd University Hospital, Casablanca, Morocco \\ ${ }^{2}$ Department of ENT and Facial Neck Surgery, "20 August” Hospital, Ibn Rochd University Hospital, Casablanca, \\ Morocco
}

*Corresponding author: Zine el Abidine H, Department of ENT and Neck Surgery, "20 August” Hospital, Ibn Rochd University Hospital, Casablanca, Morocco, Tel: 00212662405006, E-mail: zeahouda@gmail.com

Citation: Zine el Abidine H, Moustaader H, Bajja MY, Rouadi S, Abada R, et al. (2016) Facial Dog Bites: 10 Case Report. J Case Rep Stud 4(5): 502. doi: 10.15744/2348-9820.4.502

Received Date: March 31, 2016 Accepted Date: October 26, 2016 Published Date: October 28, 2016

\begin{abstract}
The face is the most vulnerable area in the dog bites, the disease is an infectious emergency, aesthetic and functional. we will discuss the clinical, therapeutic and evolutionary of dog bites. Our study focuses on 10 cases recorded over 3 years.

The average age is 55 years with male predominance (4/1); 3 patients with psychiatric disorders, 4 are night guards, 2 are homeless and one patient had a total engine failure and dementia. The bite is superficial for 5 patients; the average consultation time for these patients is less than 12 hours, they received debridement and antibiotic prophylaxis with suture. One patient consulted 72 hours after the bite of which the review found a puncture wound to the neck, without functional impairment, he was put on antibiotics. The bite has been responsible for loss of substance in $50 \%$ of cases with an average waiting period of more than $24 \mathrm{~h}$ for consultation; in 2 cases there was obtained a directed healing in a time of 45 days. 3 patients have lost significant lip substance; a flap reconstruction was performed in one patient after one month, the other 2 were lost to view.

Facial dog bites are not uncommon and can take different clinical aspects, these are emergencies that require specialist multidisciplinary care to avoid the aesthetic, infectious or functional sequelae. The treatment is codified and seeks to avoid complications that can sometimes, if ignored, be fatal.
\end{abstract}

Many accidents could be avoided by educating animal owners to potential danger their pets can represent especially for children.

Keywords: Dog Bite; Support; Antibiotic Prophylaxis; Emergencies; Effects; Vaccination

\section{Introduction}

Dog bites account for 0.5 to $1 \%$ of visits to emergency surgery. They are rarely serious but can cause considerable aesthetic and functional sequelae since the face is affected in $75-85 \%$ of cases [1]. This is indeed the most vulnerable area in the dog bites, it's infringement is an infectious but also functional emergency. In Europe Dog bites remain the prerogative of the child and still pose the problem of sepsis [2]. This retrospective study aims to discuss the clinical, therapeutic and the evolution of these dog bites admitted to the ENT emergencies of Casablanca "20 August" Hospital.

\section{Material and Methods}

We have conducted a retrospective study of 10 adult patients, victims of dog bites, between January 2010 and December 2012 , at the ENT surgery emergencies of «20Aout » Hospital. The average age was 55 years (range 25-85) with a male predominance $($ sex ratio $=1 / 4)$. We included all patient within this age range, with facial or neck dog bite. One patient had a previous bite of the lower limb. Fifty percent of the biting dogs belong to neighbors, these dogs were vaccinated for rabies. Fourty two percent of the biting dog is unknown, they have not been vaccinated or confined for observation. In $8 \%$ of cases it belongs to a family member, and the dog was already vaccianted for rabies. Three patients are followed for psychiatric disorders, four are night guards, two are homeless and one patient is bedridden. The bite is superficial in 5 cases, with lesions of the lower lip in 3 cases (Figure 1). We noted a cheek injury in 1 case; and the ear (Figure 2). The patients consulted in less than 12 hours after the incident, they all benefited from trimming with suture and antibiotic prophylaxis. They also had full rabies prophylaxis including immunoglobulin, using the wistar pitman moore L503 "vaccin rabique Pasteur» at « The Pasteur Institute of Casablanca » this is unfortunately not available troughout the country. The examination of a patient who was viewed 72 hours after the bite found a puncture scar at the neck, without functional impairment after exploration; we put the patient on antibiotics. 


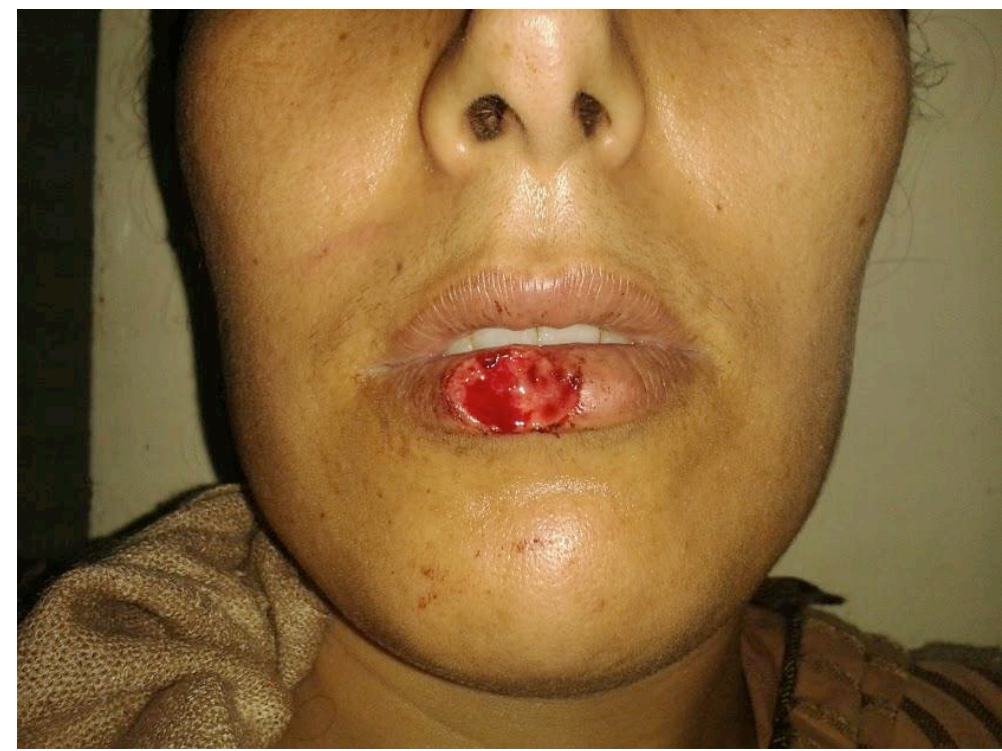

Figure 1: Bite of the lower lip in a woman with loss of substance

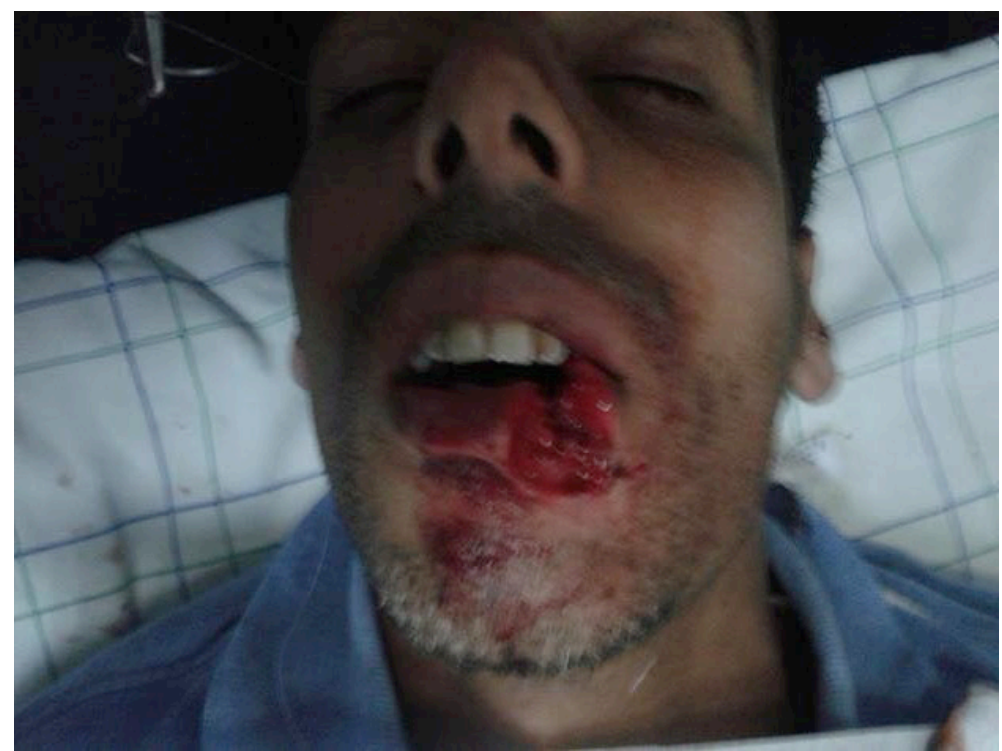

Figure 2: Dog Bite decaying of the lower lip in a young man

\section{Results}

The dog bite was responsible for loss of substance in 50\% with an average time of consultation of more than 24hours (Figure 1 ) [2]. In 2 cases we procceded to a directed healing in a time of 45 days, one of them had loss of substance of the nasal pyramid; and another with cheek injury. Three patients have losses of nasal tissue; a flap reconstruction was performed in one patient after 1 month, and the other 2 were lost to view.

\section{Discussion}

In the United Kingdom the number of the recorded injuries from dog bites and stikes increased considerably, and hospital episode statistics (HES) showed that from 1989 to 2013 the number of admissions for those injuries rose to 550\% [1]. The sex ratio varies with the age of bite victims: men are bitten more than women in the 30-39 age group $(\mathrm{p}=0.002)$; beyond 60 years, women are more bite victims than men $(\mathrm{p}=0.006)$ [2]. The patients most likely to suffer dog bite injuries of the head and neck are children. Although a number of dog breeds were identified, the largest group were pit bull terriers, whose resultant injuries were more severe and resulted from unprovoked, unknown dogs [3].

In Africa the average age is $20 \pm 12$ years and the sex ratio $\mathrm{M} / \mathrm{F}$ is 1,3 ; dogs being the primary aggressor (89.2\%), also other mammals were cited in the studies as they are implicated in very serious accidents; although rare such as horn blows, ans kicks [4].

Twenty-one percent of people bitten in the face belong to a very unfavorable social environment; $71.43 \%$ dog bites to the face are multiple and interess the central zone. The bites are deep in $77 \%$ of cases with amputation or loss of substance in $31 \%$ of cases [2,4]. 
In another study they determined that the fundamental factors that increase the probability of a dog bite to the face are as follows: the child being 2-5 years old, a single-parent context, and involvement of a German Shepherd-type dog [5].

Clinically dog bites come in many shapes, the location of the lesions varies with the age of the victim, in fact, it is estimated between $70 \%$ and $80 \%$ achievement on the face for the child. The more the child grows, the more it diversifies the location [6].

The mortality rate associated with bites is very low in France (less than two per year) as opposed to 15 per year in the US [7]. We can define as a serious bite, a bite that may be life-threatening on short or longer term. It is important to stress the importance of prehospital care. Indeed, early medicalization is a contributing factor in the evolution and prognosis $[7,8]$.

The assessment of severity is related to injuries related to the wound and associated clinical signs.

The dog bites are always septic (30\% risk of sepsis: cellulitis); indeed, they are at high risk of bacterial infection, primarily with oral flora of the biter (Pasteurella, Capnocytophaga, Eikennella, streptococci, staphylococci and anaerobes); However, only 15\% to $20 \%$ of dog bites become infected and they are in most cases of bacterial infection $[9,10]$. Examination of the wound is done simultaneously with prolonged high water cleaning and lathering on effective rabies, tetanus prevention is attributable to the support it is obvious to check the validity of tetanus protection patient $[10,11]$.

The severity of the injury is classified according to the type of lesion emergency / - gravity 1: no broken skin or scratch - gravity 2: superficial wound (beyond scratch or scrape) with no associated injury - gravity 3: deep wound or associated with other injuries (fracture, tendon damage, etc.) [12].

This local clinical examination is supplemented if necessary by radiographs and an overall balance sheet for possible injuries or associated fractures or flaws that may decompensation $[8,9]$.

Following this assessment, among the expected severity factors we include the age and sex of the person who was bitten and many features on the biter dogs: age, sex, race, height, usual behavior terms of aggressiveness and type of attack that led to the bite. Repeat offenders dogs represent $27 \%$ of cases. In $96.1 \%$ of cases, the dog is part of the entourage of the child, family, neighbors, friends and in $47 \%$ of cases, there is a determined circumstance to this bite [11].

Mechanically, the bite wounds are a combination of pinching, crushing, breaking, laceration, perforation, tearing, detachment and avulsion of fabrics with dog teeth. The bite wounds often have a misleading appearance. due to the high elasticity of the skin, especially in the neck and abdomen, the superficial appearance of the wound can be limited to punctate lesions while the underlying tissue may be severely affected $[11,12]$. For the bites of the face, the important secondary edema prevents suture on the $3^{\text {rd }}$ day. The local blood supply and good immunity of patients determine the risk of infection, it is possible to make fine sutures on condition of immediate antibiotic therapy and possible drainage. This attitude also gives aesthetic results much higher. If significant wound, debridement and thorough cleaning under general anesthesia with excising contused tissue is necessary in a surgical environment. Antibiotic treatment is systematic because of the risk of pasteurellose particularly if it appears within days pain and edema: tetracyclines except against indications. Prevention against tetanus based on the recall of tetanus toxoid vaccine and anti-tetanus globulin [13].

In our series all patients received preventive vaccine treatment according to the Zagreb protocole 4 injections (2JO, 1J7, 1J21) coupled to a rabies immunotherapy.

Most surgical problems concerning dog bites relate to the surgeon since it is primarily a skin aggression wich poses immediate septic problems and closure, and in the longer term the healing and finally remotely aesthetic problem with possible takeovers of plastic surgery.

Nearly half of the victims bitten (47\%) report having sequelae, mostly aesthetic (91\%). There are more effects to the bites of the head or the lower limbs; they are more common in women, when the weight of the biting dog is high, when the initial severity of the bite is high. The type of aggression and the nature of the relationship between the victim and the dog do not influence the occurrence of sequelae. One in seven of bitten patients, states that they still have pain at 16 months $[12,13]$.

\section{Conclusion}

The dog bites in adults can be in multiple clinical aspects. The management may be long and also may require many surgical interventiens for reconstruction, especially for children. It also requires multidisciplinary response and good attendance on the part of patients, which the majority of them come from disadvantaged background. Finally, many accidents could be avoided by educating animal owners to potential danger their pets may represent.

\section{Acknowledgment}

We thank all the authors who participated respectively in the realization of this study. 


\section{References}

1. Mannion CJ, Graham A, Shepherd K, Greenberg D (2015) Dog bites and maxillofacial surgery: what can we do? Br J Oral Maxillofac Surg 53: 522-5.

2. Siberchicot F, Zwetyenga N, Majoufre-Lefebvre C, Ammar-Khodja M (2002) Etiology of lip defects. Ann Chir Plast Esthet 47: 371-9.

3. O'Brien DC, Andre TB, Robinson AD, Squires LD, Tollefson TT (2015) Dog bites of the head and neck: an evaluation of a common pediatric trauma and associated treatment, Am J Otolaryngol 36: 32-8.

4. Djellalil A, Galatis N, Tamisier M, Zunino M, Mastropasqua S, et al. (2007) Evaluation of the indication sutures and antibiotics in the treatment of wounds bite cats and dogs [Évaluation de l'indication des sutures et de l'antibiothérapie dans la prise en charge des plaies par morsure de chats et de chiens]. Eur J Emerg 20: 156-7.

5. Touré G, Anqoulanqouli G, Meninqaud JP (2015) Epidemiology and classification of dog bite injuries to the face: A prospective study of 108 patients. J Plast Reconstr Aesthet Surg 68: 654-8.

6. Edmar A, Djemili S, Boumahni B, Randrianaly H, Taha S, et al. (1998) Dog bite to the neck and ischemic myocardial cerebellum and brain stem [Morsure de chien au cou et infarctus ischémique du cervelet et du tronc cérébral]. Pediatr arch 5: 694-5.

7. Brisou B, Abgrall J, Leterrier JP, Verdier M, Lepers JP, et al. (1981) Septicemia and bacteremia Pasteurella multocida General review about a new case in a subsequent staff cat bite [Septicémies et bactériémies à Pasteurella multocida Revue générale à propos d'un nouveau cas personnel consécutif à une morsure de chat]. Infect Dis Med 11:210-6.

8. Bourillon A (2004) Emergency management of bites, scratches and envenomation [Morsures, griffures et envenimations: conduite à tenir en urgence]. EMC Médecine 1:337-51.

9. Bessie D (2008) Dermatological manifestations of metabolic and infectious diseases Toxic [Manifestations dermatologiques des maladies infectieuses métaboliques et Toxiques]. Dermatol Med 2: 1-331.

10. Boillat N, Frochaux V (2008) Bites infectious animals and risk [Morsures d'animaux et risque infectieux]. Rev Med Suisse 174: 2149-55.

11. Hersant B, Cassier S, Constantinescu G, Gavelle P, Vazquez MP, et al. (2012) Facial dog bite injuries in children: Retrospective study of 77 cases [Morsures de chien à la face chez l’enfant: étude rétrospective de 77 cas]. Ann Aesthetic Plast Surg 57: 230-9.

12. Ricard C, Thélot B (2011) Factors severity of dog bites to emergencies. multicentre survey, France, May 2009-June 2010 Document type: Report / Synthesis [Facteurs de gravité des morsures de chien aux urgences. Enquête multicentrique, France, mai 2009-juin 2010 Type de document: Rapport/Synthèse] SaintMaurice: Institut de Veille Sanitaire 29.

13. Pédrono G, Ricard C, Bouilly M, Thelot B (2014) Sequelae with dog bites. sequelae of dog bites Institute of Health Multicenter Survey [Séquelles consécutives aux morsures de chien. Séquelles consécutives aux morsures de chien-Institut de veille sanitaire Enquête multicentrique] Saint-Maurice: Health Monitoring Institute 46 .

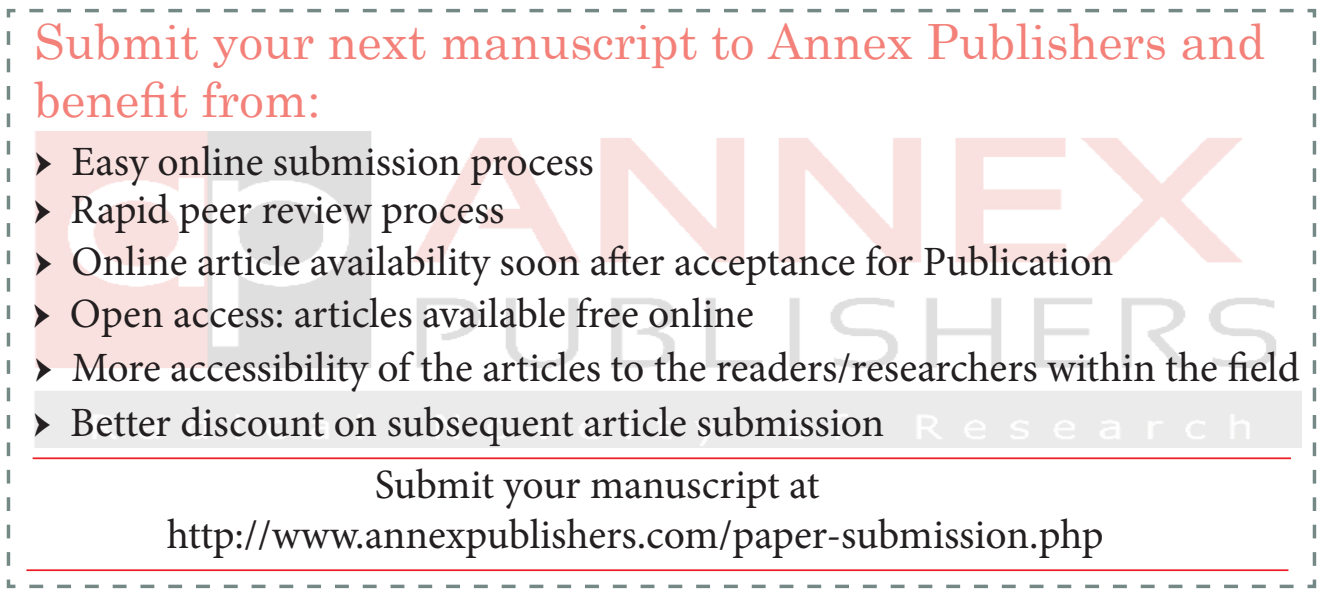

